\title{
Trata de personas en los niños, niñas y adolescentes de la comunidad Achagua, un análisis desde los procesos de restablecimiento de derechos efectuados*
}

\author{
Trafficking in persons in the children and adolescents of \\ the Achagua community, an analysis from the processes \\ of restoration of rights carried out
}

\section{Lina María Ortegón Suárez**}

Artículo de investigación

Fecha de Recepción: 13 de enero de 2021

Fecha de Aceptación: 28 de febrero de 2021

\section{Para citar este artículo:}

Ortegón Suárez, L. M. (2021). Trata de personas en los niños, niñas y adolescentes de la comunidad Achagua, un análisis desde los procesos de restablecimiento de derechos efectuados. Revista Análisis Jurídico-Político, 3(5), 201-221. https://doi.org/ 10.22490/26655489.4506

\section{RESUMEN}

Mediante una investigación cualitativa, con la aplicación de un método deductivo y el uso de diferentes herramientas como la consulta en bases de datos, estadística, referentes dogmáticos, antecedentes históricos y marco normativo, el presente artículo pretende explicar la cosmovisión de la comunidad Achagua,

\footnotetext{
* Este artículo es producto del proyecto titulado Migración y Trata de Personas, el cual se desarrolló en el grupo de investigación Derecho, sociedad y empresa (COL0201684), en la línea de investigación Derecho constitucional, procesal y de masc de la Institución Universitaria Politécnico Grancolombiano.

** Abogada, especialista en Derecho Administrativo y magíster en Derecho Procesal por la Universidad Libre de Colombia. Conciliadora en Derecho formada en la Cámara de Comercio de Bogotá. Coordinadora académica y docente de pregrado de Instituto Universitario de Profesiones Gerenciales (IUPG). ORCID: https://orcid.org/0000-0001-99715070 Correo electrónico: Imortegon@poligran.edu.co
} 
para luego abordar la trata de personas, su tránsito normativo y modalidades. Esto para dar lugar a la explicación del interés superior de los niños, niñas y adolescentes, y la manera como se da curso a los procesos de restablecimiento de derechos por parte del Instituto Colombiano de Bienestar Familiar (ICBF) cuando este es quebrantado. Cuando se trata de población indígena, se genera un análisis de los datos aportados por dicha entidad en comparación con la información proporcionada por la Fiscalía General de la Nación (FGN) frente a la comisión del delito. Esto para tratar de explicar sus posibles orígenes y consecuencias; $y$, a partir de ello, generar una serie de pautas para hacer seguimiento a esta conducta y evitar su consecución a futuro.

Palabras clave: Achagua, restablecimiento de derechos, trata de personas.

\section{Abstract}

Through qualitative research, with the application of a deductive method, using different tools such as querying databases, statistics, dogmatic references, historical antecedents and regulatory framework, this article aims to explain the worldview of the Achagua community. To then address trafficking in persons, its regulatory transit and modalities, giving rise to the explanation of the best interest of the children and adolescents and how when this is violated, the processes of reestablishing rights by the ICBF are carried out, including when it comes to the population, indigenous peoples. Generating an analysis of the data provided by said entity in comparison with the data provided by the FGN regarding the commission of the crime, to try to explain its possible origins, consequences, and from there, generate a series of guidelines to make follow-up on this behavior, avoiding its future attainment.

Keywords: Achagua, human trafficking, restoration of rights. 
Lina María Ortegón Suárez - Trata de personas en los niños, niñas y

\section{INTRODUCCIÓN}

Los Achagua ${ }^{1}$ son uno de los pueblos indígenas que habitan el territorio colombiano. El profesor José Gumilla, en su obra El Orinoco ilustrado (1955), los define como un pueblo chibcha, situado en la sabana del Orinoco y descendientes legítimos de los tigres. Se destaca que tal vez este origen mítico explicaba su comportamiento cruel (Gómez y Payán, 2017).

Colombia reconoce la diversidad étnica y cultural desde la Constitución Política de $1991^{2}$. Incluso, la Corte Constitucional otorgó a las comunidades indígenas la calidad de sujetos de derechos (Corte Constitucional de Colombia, Sentencia T-380/93) $\mathrm{y}$, con ello, una protección en cuanto a sus valores, creencias, actitudes y conocimientos, con el propósito de evitar cualquier tipo de supresión, mitigación y, en general, cualquier acto que pueda llevar a su extinción.

El profesor Daniel Aguirre, en su artículo Nuestras condenadas lenguas colombianas (2013), menciona que de las lenguas indígenas se tienen datos de menos de 200 hablantes en la comunidad Achagua del Meta, cerca de desaparecer (Espinosa Arango, 2015).

Es importante conocer la cosmovisión de los Achagua para entender sus orígenes y costumbres, y de esta manera identificar el papel de los niños, niñas y adolescentes (NNA), puesto que son alarmantes las cifras que arroja el Instituto Colombiano de Bienestar Familiar (ICBF) en relación con esta comunidad. Se evidencian 39572 ingresos de menores a procesos de restablecimiento de derechos, debido al abandono de sus progenitores, violencia, consumo de sustancias psicoactivas, entre otros motivos de ingreso, desde el año 2011 hasta el año 2018, de los cuales 2149 se deben a la trata de personas en diferentes modalidades (ICBF, 2018).

1 También conocidos como ajagua, axagua, ajawa o Xagua.

2 Artículo $7 .^{\circ}$. El Estado reconoce y protege la diversidad étnica y cultural de la Nación colombiana. 
La Organización Internacional del Trabajo (OIT, 2014) reveló que al menos 21 millones de personas sufren la trata de personas en el mundo. Por su parte, la Organización de las Naciones Unidas reveló que el $30 \%$ de las víctimas son niños (7 \%) y niñas $(23 \%)$ (ONU, 2018). Estos datos fueron publicados en conmemoración del Día Mundial de la Trata de Personas, revelando además que, en 2018, la Fiscalía General de la Nación inició 271 procesos relacionados con este delito, y entre enero y abril de 2019 se registraron 74 presuntos casos (Unicef, 2019).

La Oficina de las Naciones Unidas contra la Droga y el Delito elaboró el informe global sobre trata de personas, en el cual data que los niños son víctimas en la modalidad de trata de personas con fines de trabajos forzados en un $50 \%$, y de explotación sexual en un $27 \%$, así como de otras formas de explotación como la mendicidad forzada, niños soldados y actividades criminales forzadas. Las niñas fueron víctimas de explotación sexual en un $72 \%$ y bajo la modalidad de trabajos forzados en un $21 \%$ (UNODC, 2018).

¿Cómo se puede prevenir la trata de personas, especialmente en NNA de la comunidad Achagua, sin el quebrantamiento de su identidad étnica y cultural, salvaguardando sus costumbres y rescatando el derecho fundamental a tener una familia?

El presente artículo pretende abordar los fundamentos teóricos, legales, jurisprudenciales, a nivel nacional e internacional en relación con los Achagua, así como los procesos de restablecimiento de derechos de los NNA y la trata de personas, mediante el análisis de los datos del ICBF clasificados por género, ubicación, modalidad y año en que se presentó el hecho. Esto con el propósito de analizar el contexto histórico de cada región y otorgar unas consideraciones finales que expongan unas pautas que deban seguirse y, de esta manera, evitar la consecución del delito y conservar la integridad y dignidad de la comunidad, en especial de los niños, niñas y adolescentes que hacen parte de ella.

Se debe mencionar que se trata de un escrito de revisión bibliográfica, pues en la recolección de datos no se tuvo contacto con la comunidad, ni acceso a los casos - los cuales revisten confidencialidad- de los NNA que pasaron por los procesos administrativos 
Lina María Ortegón Suárez - Trata de personas en los niños, niñas y

para lograr la garantía de sus derechos fundamentales. Sin embargo, los resultados permiten identificar las zonas geográficas con mayor impacto, para establecer pautas en una intervención temprana sin el quebrantamiento de las ideologías étnicas y culturales propias e identificadas en la investigación.

\section{La cosmovisión de los Achagua}

Según estadísticas del Departamento Administrativo Nacional de Estadística (DANE), el pueblo indígena Achagua pasó de tener una población de 796 en el Censo General de 2005 a 980 personas en el Censo Nacional de Población y Vivienda de 2018. Su nombre traduce la gente del río, lo cual se debe a su georreferenciación, pues la gran mayoría se encuentra ubicada en Puerto López (Meta), cerca de los ríos Meta, Casanare y Ariporo (DANE, 2018).

A diferencia de otras comunidades indígenas, los Achagua desde siempre se han caracterizado por ser sedentarios. Su referente histórico los ubica en los Llanos Orientales, incluso antes de la época de la colonización, que trajo consigo nuevas creencias. Un ejemplo de ello corresponde a los jesuitas, quienes modificaron irrevocablemente su cultura. Sin embargo, conservan su actividad económica primaria: la pesca, la agricultura y, eventualmente, la cacería (Ministerio del Interior, 2018).

En cuanto a su organización familiar, se evidencia que la autoridad recae en el progenitor, quien, como un pater familias ${ }^{3}$, se convierte en el pilar de los hogares de sus hijas al constituirse las nuevas familias, todos habitando un mismo espacio. Es natural que, con el tiempo, el nuevo padre de familia construya su resguardo (Organización Nacional Indígena de Colombia [ONIC], 2018).

En relación con los niños, niñas y adolescentes, en un estudio aplicado que se adelantó para evidenciar la diversidad religiosa

3 Noción del derecho romano que define al hombre como el jefe único. Una especie de monarca que concentraba en sí todos los poderes, siendo a la vez sacerdote, juez y dueño o propietario único de la familia (Moreno, Arribas y Carrasco, 2019). 
al interior de los Achagua, se identificó que las tradiciones son trasmitidas de las abuelas a las niñas mediante consejos sobre cómo comportarse; esto mientras las peinan y las envían a distribuir la comida entre los invitados. Por último, les aplican ají en la boca para hacerlas más fuertes y valientes ante la vida (Bolaños Motta y Astaiza Grande, 2019).

El autor señala que esta es la manera en la que se desenvuelve un conjunto de pautas de crianza y el desarrollo socioafectivo de los niños y las niñas (Cuervo, 2010), para garantizar de esta manera los valores, en manos de las mujeres. De igual forma, se evidencian otras costumbres propias de la comunidad en relación con los niños, quienes ejercen la cacería, la recolección de frutos y la preparación de alimentos (Bolaños Motta y Astaiza Grande, 2019). Estas prácticas están lejos de ser riesgosas, pues la estrecha relación que tienen con la naturaleza los envuelve en un acto de respeto, donde se reconoce el curso natural de la cadena alimenticia y la salvaguarda de la Madre Tierra.

Antes de abordar las nociones jurídicas relevantes frente a la trata de personas y los procesos de restablecimiento de derechos de los NNA, es importante mencionar que desde la carta suprema se contempla el Estado social de derecho y el pluralismo, el cual, para el maestro Cabedo en sus estudios de América Latina (2012), representa el derecho de los pueblos indígenas sobre los impuestos en la época de la Colonia (Figuera Vargas y Ariza Lascarro, 2015).

El Derecho Internacional de los Derechos Humanos (DIDH) le otorgó a las comunidades indígenas la condición de pueblos, lo que tornó imperativo al interior de los Estados el reconocimiento de la condición de autodeterminación. De allí el surgimiento de la jurisdicción especial indígena, contemplada en el artículo 246 de la Constitución Política de 1991. Esta supone "[...] una subordinación de las prácticas cotidianas a una doble normatividad. Por una parte, el derecho tradicional y por otra el impuesto por el actor hegemónico" (Hernández, 2012), toda vez que están supeditados a la carta suprema y a la ley. 
Lina María Ortegón Suárez - Trata de personas en los niños, niñas y

\section{LA TRATA DE PERSONAS, TRÁNSITO NORMATIVO Y MODALIDADES}

A nivel internacional, esta problemática se ha abordado mediante diversos convenios, de manera específica y segmentada por género. Todo en la búsqueda de la garantía de los derechos humanos desde el año 1904 con el Acuerdo internacional para la supresión de la trata de blancas, hasta el Convenio para la represión de la trata de personas y de la explotación de la prostitución ajena de 1949, vigente hasta el año 2000. En este mismo año se expidió el Protocolo de Palermo, el cual define la trata de personas ${ }^{4}$ y menciona que los fines de este son: la prevención de este delito especialmente en niños y mujeres, la protección a víctimas y la cooperación entre los Estados parte. De igual manera, aduce que la penalización estará en cabeza de los Estados al generar su ratificación interna (UNODC, 2010).

En Colombia, con antelación a este pronunciamiento internacional, ya se contaba con un marco normativo, que data desde el decreto 1974 de $1996^{5}$, mediante el cual se creó el Comité Interinstitucional para la Lucha contra el Tráfico de Mujeres, Niñas y Niños y la ley 599 de 2000 —actual código penal—. Luego, se expidió la ratificación interna del Protocolo de Palermo, mediante la expedición de la ley 800 de 2003, con las modificaciones de la ley 985 de 2005, que adicionó la trata de personas como un delito común en la ley 906 de 2004 (Código de Procedimiento Penal) (Reyes, 2018).

El estamento internacional no especifica el tratamiento que se debe dar a los casos de trata de personas pertenecientes a comunidades indígenas, pero sí precisa las necesidades especiales de la víctima al enfatizar en los niños, en relación con su alojamiento,

4 Artículo 3. a) Por "trata de personas" se entenderá la captación, el transporte, el traslado, la acogida o la recepción de personas, recurriendo a la amenaza o al uso de la fuerza u otras formas de coacción, al rapto, al fraude, al engaño, al abuso de poder o de una situación de vulnerabilidad o a la concesión o recepción de pagos o beneficios para obtener el consentimiento de una persona que tenga autoridad sobre otra, con fines de explotación. Esa explotación incluirá, como mínimo, la explotación de la prostitución ajena u otras formas de explotación sexual, los trabajos o servicios forzados, la esclavitud o las prácticas análogas a la esclavitud, la servidumbre o la extracción de órganos.

5 Modificado por el decreto 1456 de 1997. 
educación, cuidado, seguridad y reparación, confiando en la normatividad interna de cada país, la regulación por parte de entidades judiciales y administrativas (ONU, 2000).

Por su parte, el código penal (Ley 599, 2000) tipifica la trata de personas como el acto cometido por todo aquel que "[...] capte, traslade, acoja o reciba a una persona, dentro del territorio nacional o hacia el exterior, con fines de explotación" (Artículo 188-A). El código impone una pena privativa de libertad de 13 a 23 años y una multa que oscila entre los 800 y 1500 salarios mínimos legales mensuales vigentes (SMLMV) al momento de la imposición de la pena.

Como ítem relevante en la investigación, se identifica que, en la norma en mención, dentro de las circunstancias de agravación punitiva, está la comisión del delito contra persona menor de 18 años (niños, niñas y adolescentes). Pero, una vez más, hay ausencia en cuanto a un pronunciamiento de la víctima en relación con su identidad étnica.

Luego, mediante la Ley 1453 de 2011 se tipificó una nueva conducta como delictiva, adicionándola a la ley 906 de 2004. Esta especifica que el victimario es todo aquel "[...] que intervenga en cualquier acto o transacción en virtud de la cual un niño, niña o adolescente sea vendido, entregado o traficado por precio en efectivo o cualquier otra retribución a una persona o grupo de personas" (Artículo 188-C). Asimismo, contempla la pena máxima - aplicable a otros delitos sexuales y contra la integridad de los NNA- de 60 años. Esta norma entró en vigor a partir de su promulgación, el 24 de junio de 2011, por lo que las cifras analizadas del ICBF deberían arrojar cantidades similares a las de la Fiscalía General de la Nación en la comisión de este delito para los años conexos.

La trata de personas, como lo mencionan Hurtado y Pereira (2018) - en un estudio reciente que trata de explicar este acto por terceros con fines de explotación sexual en las mujeres-, puede ser abordada desde diferentes perspectivas, como se ha observado hasta ahora, desde el ámbito internacional de los derechos humanos y desde la especialidad del derecho penal, que está ampliamente esbozada en Colombia, entre otros. 
Lina María Ortegón Suárez - Trata de personas en los niños, niñas y

Las modalidades de trata de personas fueron presentadas en un estudio que adelantó el Ministerio del Interior en el año 2009, en colaboración con la Universidad Nacional y la UNODC. Este estudio señala que dicho delito "[...] tiene diversas formas de expresión, las cuales dependen del propósito de la explotación y del escenario en donde se mueve" (Valencia, 2009).

Dicho estudio distingue diferentes propósitos de quien comete el acto, sin olvidar que, en la mayoría de los casos, sus fines son lucrativos. Entre ellos están: 1) la explotación sexual (prostitución, pornografía, turismo sexual); 2) la explotación laboral (mendicidad, ventas callejeras, servicio doméstico, agricultura, pesquería, minería, construcción o trabajo en fábricas); 3) el establecimiento de relaciones filiales (matrimonio servil y adopciones irregulares con la posterior explotación); 4) la comisión de ilícitos (participación en diferentes delitos como transporte de droga y robos), 5) la comercialización de órganos y tejidos; y 6) el conflicto armado (informantes, combatientes, servicios domésticos y servicios sexuales) (Valencia, 2009).

De esta manera, se define el marco conceptual, supranacional y legal que aborda la trata de personas. Esto sin escudriñar en detalle lo que la doctrina tiene por decir sobre investigaciones adelantadas con la finalidad — en la mayoría de los casos- de generar políticas públicas, de una manera suficiente, para entender el impacto que ha tenido en los niños, niñas y adolescentes de la comunidad Achagua. Este pueblo indígena que, pese a tener autonomía, se somete a las reglas administrativas del ICBF ante el restablecimiento de derechos de sus menores.

\section{EL INTERÉS SUPERIOR DE LOS NNA Y LOS PROCESOS DE RESTABLECIMIENTO DE DERECHOS}

El interés superior de niños, niñas y adolescentes (Constitución Política de Colombia, 1991) es un postulado que exige el análisis de las diferentes disposiciones internacionales en materia de de- 
rechos humanos ${ }^{6}$. Consiste en reconocer la naturaleza integral de sus derechos y tiene por finalidades la garantía y el goce pleno y efectivo de todos los derechos reconocidos por la Convención de los Derechos del Niño, así como el desarrollo unitario e integral de estos (Pradilla-Rivera, 2011).

Ese interés superior - Código de Infancia y Adolescencia, 2006(Ley 1098 de 2006), como un postulado sustancial, debe ser la consideración primordial para la evaluación y ponderación ${ }^{7}$ de los distintos intereses que puedan entrar en conflicto. También es un principio jurídico hermenéutico fundamental, puesto que en los casos en que una norma jurídica admita más de una interpretación, se debe elegir la que satisfaga de manera más efectiva los derechos de los NNA, y logra una relevancia procesal en el evento en que se deba tomar una decisión que los afecte, pues se deben ponderar las repercusiones (Pabón Parra, 2018).

El fundamento constitucional se ubica en los artículos 1, 2, 5, 44, 45 y 50 , en donde se encuentra la dignidad humana, el derecho a tener un nombre, conocer el origen, tener una familia y no ser separados de ella, y la prevalencia de sus derechos sobre los de los demás (Constitución Política de Colombia, 1991).

El Código de Infancia y Adolescencia hace énfasis en los derechos de los NNA de los pueblos indígenas y demás grupos étnicos, y decreta que gozarán de los derechos consagrados en la carta suprema y en los instrumentos internacionales de derechos humanos, sin perjuicio de los principios que rijan su cultura y organización social (Ley 1098 de 2006, Artículo 13).

6 Convención Americana sobre Derechos Humanos.

7 La ponderación es una ley con una sola regla, “[...] cuanto mayor sea el grado de no satisfacción o restricción de un principio, tanto mayor tiene que ser la importancia de la satisfacción del otro" (Alexy, 2007). En el primer paso se establece el grado de no satisfacción o restricción de uno de los principios; en el segundo, la importancia de la satisfacción del principio contrario; y, en el tercero, se determina si la importancia de la satisfacción del principio contrario justifica la no satisfacción o restricción del otro principio (Beade y Clérico, 2011). 
Lina María Ortegón Suárez - Trata de personas en los niños, niñas y

En línea con lo anterior, pese a hacer parte un pueblo indígena con autonomía, la comunidad Achagua se encuentra amparada por los mecanismos administrativos que se han generado para la garantía y el restablecimiento de sus derechos. Una vez son quebrantados, se deja en un segundo plano el aseguramiento del respeto por su diversidad étnica y cultural, siempre y cuando sus procesos y costumbres no sean violatorios de los derechos humanos (Linares Cantillo, 2007).

El proceso de restablecimiento de derechos (Ley 1098 de 2006, Artículo 50) inicia cuando es flagrante la vulneración del niño, niña o adolescente, como un mecanismo administrativo en cabeza del ICBF, para garantizar la dignidad, vida e integridad de estos. Para ello, se genera una intervención en la que se aparta al menor de la persona con la cual se encuentre en el momento, que no necesariamente son sus progenitores, cuidadores o custodios, pues también lo serán sus victimarios.

Una vez el menor inicia el proceso de restablecimiento de derechos, queda bajo la custodia del Estado, para garantizarle de esta manera su alimentación, educación y cuidados, ya sea en las regionales o con las madres comunitarias. Lo anterior en línea con los parámetros internacionales esbozados con antelación, sin olvidar que esta medida es de carácter temporal, pues en cumplimiento de los estamentos constitucionales lo que se busca es la reubicación del menor con su familia extensa o el retorno a su hogar, si las condiciones que dieron origen a la apertura de la investigación se superan.

Cuando no se logra la unificación familiar de los menores o el regreso a su entorno, puede deberse a que nadie los reclama o a que sus familiares interesados no cumplen con las condiciones socioeconómicas necesarias para garantizar una formación digna y adecuada. En estos casos se inicia un proceso de homologación con fines de declaratoria de apertura de proceso de adopción (Ley 1908 de 2006, Artículo 22). Este acto administrativo está sujeto al control judicial posterior; los fundamentos de dicho señalamiento reposan en la jurisprudencia de la Corte 
Constitucional ${ }^{8}$ y en algunas sentencias del Consejo de Estado, que recuerdan que cuando dicho acto se lleva con extranjeros puede llegar a ser irrevocable (Estrada et ál., 2018).

Los niños del pueblo Achagua fueron sujetos de procesos de restablecimiento de derechos de 2011 a 2018, por razones como el abandono, acoso escolar (bullying), entrega voluntaria de sus consanguíneos para adopción, desnutrición, víctima de delitos sexuales o de violencia intrafamiliar, condición de calle y, en gran medida, por la intervención de grupos armados mediante amenazas de muerte o reclutamiento ilegal, desplazamiento forzado, huérfanos a causa del conflicto armado, entre otros (ICBF, 2018).

A pesar de las modalidades de trata de personas identificadas, para la autoridad administrativa —en su estadística — existe una distinción entre lo que tabulan y presentan como trata de personas y la condición de calle o intervención de grupos armados, por lo que las cifras presentadas son las que institucionalmente han sido reconocidas.

\section{LOS PROCESOS DE RESTABLECIMIENTO DE DERECHOS en el pueblo Achagua de 2011 A 2018 POR tRatA de PERSONAS Y LOS DATOS DE LA FGN}

Con el propósito de conocer la relación y coherencia que existe en los datos reportados a nivel nacional, se toma la información oficial reportada por la Fiscalía General de la Nación sobre hecho victimizante de manera general; es decir, sin tener la posibilidad de discriminar en relación con las cualidades de las víctimas. Este muestreo se hace en el periodo de referencia, en contraste con los datos reportados por el ICBF para la misma época, pero de una manera más detallada, que incluye la zona geográfica donde se interviene el menor y los datos específicos del pueblo indígena Achagua.

8 Algunas sentencias como la T-502 de 2011, T-044 de 2014 y C-104 de 2016 mencionan el carácter de subsidiariedad. 
Lina María Ortegón Suárez - Trata de personas en los niños, niñas y

En el año 2011 se presentaron seis casos de adolescentes mujeres por trata de personas en la modalidad de explotación sexual, cuatro de ellos en Antioquia y dos en Chocó (ICBF, 2018). En este mismo año, sin distinciones por condiciones de género, edad o pertenencia a un pueblo indígena o grupo étnico, se presentaron 44 casos, de los cuales solo uno de ellos bajo la ley 906, que se enmarca en el tipo penal de trata de personas bajo agravación punitiva por tratarse de una persona menor de 18 años (Gov.co Datos abiertos, 2021).

Para esa época, Juan Manuel Santos cumplía un año posesionado como presidente en su primer mandato, periodo en el que el país seguía inmerso en la guerra interna que englobaba su historia. En este mismo año se llevó a cabo la operación Odiseo por parte de la Fuerza Aérea Colombiana, en la que se causó el deceso de Alfonso Cano, uno de los máximos exponentes del grupo ilegal armado de las Fuerzas Armadas Revolucionarias de Colombia (FARC).

En materia de trata de personas o políticas públicas regionales relacionadas, la UNODC, en colaboración con la Alcaldía de Medellín, elaboró un estudio descriptivo (2015) con datos consecuentes a lo enunciado de 2011 a 2015. En este se evidencia la intervención de bandas criminales (Bacrim) y organizaciones delincuenciales (Odin), las cuales influyeron en el alto flujo de casos presentados. Esto aunado a factores de riesgo asociados como la baja autoestima, bajo nivel de escolaridad y antecedentes de violencia intrafamiliar o abuso sexual.

Para el 2012 no se evidenció un cambio drástico. Se presentaron 13 casos, de los cuales cinco eran de mujeres, tres de ellas adolescentes y dos infantes; y ocho casos de hombres, cinco de ellos niños y tres infantes. Del total, habían tres casos bajo la modalidad de explotación sexual en el departamento de Antioquia y los demás por trabajo infantil en las regionales de Norte de Santander, Córdoba y Atlántico (ICBF, 2018). Para este mismo año, en la Fiscalía no se reportaron hechos en relación con menores de 18 años (Gov.co Datos abiertos, 2021).

En un contexto general, en el año 2012, la población indígena Nasa sacó de su territorio a casi 100 soldados de la base militar del 
Cauca, con el propósito de recuperar de su territorio. Se presentó una masacre en Santa Rosa de Osos, al Norte de Antioquia por parte de las bandas criminales (Bacrim), y falleció Griselda Blanco, más conocida como la reina de la cocaina, y Lorena Henao Montoya, viuda de uno de los capos más temidos del cartel del Valle.

A esta estadística ingresó una modalidad hasta el momento no abordada: el trabajo infantil. En un boletín, el ICBF reportó las proyecciones del observatorio del bienestar de la niñez, que abordó con una doble mirada el trabajo infantil en Colombia (2013). En dicho estudio se presentó un análisis cualitativo y cuantitativo, en el que se identificaron los hallazgos en cuanto a número de víctimas en el año 2011 y la implementación de la ruta para la atención de casos a través de los procesos de restablecimiento de derechos. Se evidenció que los niños y adolescentes, como víctimas de esta modalidad, tienen un porcentaje más elevado en relación con las niñas; y que la pobreza y el bajo nivel de escolaridad de sus progenitores son un detonante en la comisión del acto.

Para el año 2013, el delito aumentó sustancialmente: 989 casos, de los cuales fueron víctimas 447 niñas, 541 niños y uno no identificado. Se reconocieron 821 casos en la modalidad de trabajo infantil, 161 por explotación sexual, uno por extracción ilegal de órganos, cuatro por mendicidad ajena y dos por trabajos forzados o prácticas similares a la esclavitud. Es importante señalar que, a nivel territorial, se observa un impacto en más de 28 regiones del país (ICBF, 2018). En contraste con las denuncias presentadas por estos hechos para la misma época, estos datos son alarmantes, toda vez que solo se tiene registro de un caso en el departamento de Risaralda por trata de personas bajo agravación punitiva por tratarse de persona menor de 14 años (Gov.co Datos abiertos, 2021).

En comparación con periodos anteriores, los casos para el 2014 aumentaron considerablemente (1066), en los que la trata de personas se cometió contra 519 niñas y 547 niños, 857 casos en modalidad de trabajo infantil, 202 casos de explotación sexual, dos casos por mendicidad ajena, dos por trabajos forzados o prácticas 
Lina María Ortegón Suárez - Trata de personas en los niños, niñas y

similares a la esclavitud y tres por una modalidad nueva hasta el momento, el turismo sexual. Nuevamente se evidenció la presencia en más de 28 regiones del país (ICBF, 2018). Para este mismo año, se presentaron a nivel nacional cuatro casos para la comisión del delito bajo agravación punitiva por tratarse de persona menor de 14 años (Gov.co Datos abiertos, 2021).

Las cifras reportadas para el 2013 y 2014 son un flagrante riesgo no solo para los NNA, sino para el pueblo indígena en sí, pues se amenaza directamente la posibilidad de conservar la tradición de sus costumbres, la connotación de familia y el sedentarismo. Esto en relación con los datos reportados por el DANE en cuanto a población, los cuales fueron ratificados por el Ministerio del Interior para la fecha. No hay un acatamiento a la jurisprudencia reiterada de la Corte Constitucional en el sentido de la prevalencia y conservación de las comunidades indígenas, a pesar de los estudios adelantados.

El contexto histórico y las cifras plantean que el pueblo Achagua al movilizarse fuera de su territorio sufre los padecimientos del conflicto armado interno inherente a este país. Del análisis estadístico efectuado se puede evidenciar que, pese a iniciarse los procesos de restablecimiento a causa de la trata de personas en sus diferentes modalidades, ninguno de ellos ocurre en su región. Los menores ingresan bajo la tutela del Estado en otras regiones apartadas, diferentes a las que normalmente habita su comunidad. Ahora, otro factor de riesgo que se debe analizar corresponde a las finalidades de la trata de personas; entre ellas, el sostenimiento de sus familias.

En el 2015 se evidenciaron 30 casos, cifra aparentemente alentadora en relación con los años anteriores, pues son solo datos de casos sobre los cuales tuvo conocimiento el Estado e inició alguna acción a favor de los menores. De estos casos, 22 correspondieron al género femenino y ocho casos al masculino; 20 casos por trabajo infantil y 10 por explotación sexual (ICBF, 2018). Para este mismo año, en la Fiscalía no se reportaron actos delictivos en este sentido con menores de 18 años (Gov.co Datos abiertos, 2021). 
En los años 2016, 2017 y 2018 se mantuvo una constante de 16, 15 y 14 casos de restablecimiento de derechos en niños, niñas y adolescentes en la comunidad Achagua por parte del ICBF. Según las cifras, los casos reportados en el 2016 correspondieron a la trata de persona bajo la modalidad de explotación sexual y trabajo infantil; y en los dos últimos años objeto de estudio, únicamente bajo la modalidad de trabajo infantil (ICBF, 2018). De acuerdo con los datos de la Fiscalía, para este periodo solo registró un caso en 2017 y tres casos en 2018 por trata de personas bajo agravación punitiva por tratarse de persona menor de 14 años (Gov.co Datos abiertos, 2021) (tabla 1).

Tabla 1. Síntesis datos reportados ICBF y FGN (2011-2018)

\begin{tabular}{|ccc|}
\hline Año & $\begin{array}{c}\text { Procesos de restablecimiento de } \\
\text { derechos de NNA de la comunidad } \\
\text { Achagua - ICBF }\end{array}$ & $\begin{array}{c}\text { Denuncias presentadas por } \\
\text { trata de personas con menor de } \\
\text { edad - FGN }\end{array}$ \\
\hline 2011 & 6 & 1 \\
2012 & 13 & 0 \\
2013 & 989 & 1 \\
2014 & 1066 & 4 \\
2015 & 30 & 0 \\
2016 & 16 & 0 \\
\hline 2017 & 15 & 1 \\
2018 & 14 & 3 \\
\hline Total & $\mathbf{2 1 4 9}$ & $\mathbf{1 0}$ \\
\hline
\end{tabular}

Fuente: elaboración propia.

En este sentido, los datos que arroja la investigación generan, entre otros, conclusiones mediante inferencia en relación con el seguimiento de estos casos por la Fiscalía General de la Nación. En principio, la trata de personas es un delito susceptible de denuncia, lo que implica que no puede ser concluido por conciliación ante la Fiscalía y debe investigarse, incluso de oficio, la comisión de los hechos. A todas luces, las cifras demuestran que estos actos 
Lina María Ortegón Suárez - Trata de personas en los niños, niñas y

están impunes, aún más cuando se trata de datos nacionales. Si los hechos que dieron lugar a la intervención por parte del ICBF para el establecimiento de derechos de estos NNA de la comunidad Achagua no se han presentado ante la autoridad judicial en lo penal, se está permitiendo su consecución a futuro desde las instituciones.

\section{Consideraciones finales}

La inconsistencia en los datos recopilados por las instituciones es notoria, incluso desde el establecimiento de la población censada. De acuerdo con las cifras suministradas por el DANE, se registraron 980 para el 2018, lo cual no coincide con el ingreso a los procesos de restablecimiento de derechos en el ICBF de 2011 a 2018 que, por los diferentes motivos, asciende a 39 572, de los cuales 2149 se ubican en el grupo de las diversas modalidades de trata. En este punto, se sugiere que las entidades trabajen en articulación y colaboración mutua para trazar sus datos y evidenciar si dicha población se encuentra en la informalidad o los funcionarios no están dando un uso adecuado a los registros étnicos al inflar o disminuir las cifras reales.

Otra inconsistencia importante que arroja el muestreo es aquella que constantemente se evidencia entre las cifras del ICBF y las que comparte la FGN, ya que esta última entidad no discrimina en la tipificación del delito; es decir, si este se comete contra un miembro de comunidad indígena. Esto impide evidenciar si existió un seguimiento a estos casos de restablecimiento de derechos en niños, niñas y adolescentes por parte de la autoridad en derecho penal, con el propósito de llevar a cabo la investigación y consecuente sanción por la comisión de estos delitos, o si continúan en la impunidad.

La prevención frente a la comisión del delito de trata de personas ha sido abordada tanto por entidades internacionales como nacionales investidas con tal autoridad. Desde el mismo Protocolo de Palermo (2000) se establecieron las pautas que deben 
ser adoptadas por los Estados miembro. En Colombia, dichas medidas se encuentran soportadas en la normatividad vigente en la especialidad de derecho penal; sin embargo, en la estadística oficial reportada bajo la Ley 906 de 2004, no se evidencian investigaciones criminales en relación con el delito de la trata de personas en menor de edad.

El ICBF, como entidad administrativa investida para adelantar los sumarios en relación con los procesos de restablecimiento de derechos de niños, niñas y adolescentes, ostenta una estadística útil para identificar factores de riesgo zonales o por edad del menor. Sin embargo, dentro de sus protocolos y publicaciones no enfatizan en el tratamiento de dicha situación, como sí lo hacen con otras temáticas como el trabajo infantil. Por ello, es necesario señalar la falta de estudios cualitativos y cuantitativos que permitan elaborar planes de acción para mitigar el alza en las cifras reportadas.

Las diferentes autoridades nacionales facultadas para intervenir en los casos no cuentan con un protocolo diferenciador que garantice la salvaguarda de las costumbres de los niños, niñas y adolescentes cuando provienen de un pueblo indígena, lo que pone en riesgo su extinción. Esta barrera se evidencia desde la redacción de la norma, que señala que, incluso cuando las costumbres sean riesgosas para la integridad del NNA, la entidad estará facultada para iniciar el proceso de restablecimiento de derechos.

Se sugiere el desarrollo de estudios sociodemográficos que permitan identificar las condiciones socioeconómicas de los pueblos indígenas, el acceso a educación y la posibilidad de fomentar su cultura sin transgredirla. Esto con el propósito de establecer los factores de riesgo frente a la trata de personas, especialmente en la modalidad de explotación sexual en niñas y el trabajo infantil en niños. En este sentido, se debe establecer si los ingresos económicos para la familia son un móvil y, a partir de allí, generar políticas públicas —especialmente en la región del Meta- que permitan prolongar el sedentarismo de la comunidad Achagua y su continuidad en condiciones de dignidad e igualdad entre todos. 
Lina María Ortegón Suárez - Trata de personas en los niños, niñas y

La comunidad Achagua es un pueblo indígena con estructura patriarcal, razón por la cual se recomienda que las entidades estatales reconozcan esta figura de autoridad y propendan por el retorno de los niños, niña y adolescentes a su entorno en condiciones seguras y estables, para garantizar la conservación de sus ideologías y el traspaso de sus saberes. Es importante reconocer que el delito de trata de personas no es la única causal que se evidencia para el inicio de las actuaciones administrativas, por lo que se debe trabajar de la mano con la comunidad, en pro del interés superior del menor.

Los datos de las entidades gubernamentales no son coincidentes, por lo que los casos en los que intervino el ICBF no corresponden a las cifras reportadas por la FGN para las fechas abordadas en el presente estudio. Se recomienda evidenciar la eficacia de las rutas establecidas para detener las redes criminales, así como el contexto histórico y cultural en el que acontecieron los casos, pues la presencia de estos se evidencia con mayor frecuencia en zonas azotadas por las bandas criminales.

\section{Referencias}

Aguirre Litch, D. (2013). Nuestras condenadas lenguas colombianas. El Sexante. Universidad de los Andes. https: / / bit.ly/3bHs0EM

Alexy, R. (2007). Teoría de los derechos fundamentales (2. ${ }^{\text {a }}$ ed.). Centro de estudios políticos y constitucionales. https: / / bit.ly/3qSYXm9

Beade, G. y Clérico, L. (2011). Desafíos a la ponderación. Serie de teoría jurídica y filosofía del derecho n. ${ }^{\circ}$ 57. Universidad Externado de Colombia. https:/ / bit.ly/3qOdbEC

Bolaños Motta, J, I. y Astaiza Grande, E. Z. (2019). Cosmovisión mágica y religiosidad protestante: Una mirada a las tensiones y transiciones en el mundo Achagua y Piapoco. Entramado, 15(2), 160-173. https://doi. org/10.18041/1900-3803/entramado.2.5634

Cabedo, V. (2012). Pluralismo jurídico y pueblos indígenas. Icaria.

Congreso de la República de Colombia. (2000, 24 de julio). Ley 599 de 2000. Por la cual se expide el Código Penal. Diario Oficial 44 097. https: / / bit.ly / 3qON5kJ

Congreso de la República de Colombia. (2006, 8 de noviembre). Ley 1098 de 2006. Por la cual se expide el Código de la Infancia y la Adolescencia. Diario Oficial 46 446. https: / / bit.ly / 38EtZHQ 
Congreso de la República de Colombia. (2011, 24 de junio). Ley 1453 de 2011. Por medio de la cual se reforma el Código Penal, el Código de Procedimiento Penal, el Código de Infancia y Adolescencia, las reglas sobre extinción de dominio y se dictan otras disposiciones en materia de seguridad. Diario Oficial 48110. https: / / bit.ly/2OTzCLb

Constitución Política de Colombia. (1991). Gaceta Constitucional n. ${ }^{\circ}$ 116. http:// bit.ly/2NA2BRg

Corte Constitucional de Colombia. (1993, 13 de septiembre). Sentencia T-380/93. (Eduardo Cifuentes Muñoz, M. P.). https:/ / bit.ly/3tDm7P6

Cuervo, Á. (2010). Pautas de crianza y desarrollo socioafectivo en la infancia. Diversitas: Perspectivas en Psicología, 1(6), 111-121. https:/ / bit.ly /30Ih6Io

Espinosa Arango, M. (2015). Temáticas contemporáneas. Antípoda. Revista de Antropología y Arqueología, 22, 15-17. https:// doi.org/10.7440/antipoda22.2015.01

Estrada-Jaramillo, L. M., Arango-Orozco, B. M., Carrasquilla-Zuluaga, D., Mesa-González, A. M., Vergara-Tobón, C., Noreña-González, M., Tamayo-Monsalve, M., LópezLopera, D. y Correa-Barros, J. A. (2018). Dificultades de la adopción de niños en Colombia a partir de la jurisprudencia de la Corte Constitucional entre 2011 y 2016. Civilizar: Ciencias Sociales y Humanas, 18(35), 1-12. https: / / doi.org/10.22518/usergioa/jour/ccsh/2018.2/a01

Figuera Vargas, S. y Ariza Lascarro, A. (2017). Derecho a la autodeterminación de los pueblos indígenas en el ordenamiento jurídico colombiano. Revista de Estudios Sociales, 53, 65-76. https: / / doi.org/10.7440/ res53.2015.05

Gómez Garcia-Reyes, C. y Payán Garrido, E. (2017). Iconografías y representaciones del jaguar en Colombia: de la permanencia simbólica a la conservación biológica. Antípoda. Revista de Antropología y Arqueología, 28, 131-152. https: / / bit.ly/38EQgFI

Gov.co Datos abiertos. (2 de febrero de 2021). Total de noticias criminales por delito registrados en el Sistema Penal Oral Acusatorio en la Ley 906 de 2004 y Ley 1098 de 2006 desde hechos ocurridos en 2010. https: / / bit.ly / 2QhM3Bi

Hernández, C. A. (2012). Arquetipos de pluralismo jurídico. Análisis de sus visiones. Verba Iuris, 27, 153-161. https: / / bit.ly/30HkF1y

Hurtado, M. y Pereira Villa, C. (2018). Inserción labor adversa: Otra cara del “demonio amorfo" de la trata de seres humanos. Cadernos Pagu, 53. https: / / doi.org/1 $0.1590 / 18094449201800530008$

Instituto Colombiano de Bienestar Familiar (IСBF). (2013). Observatorio de bienestar de la niñez $n .{ }^{\circ} 10$. Boletín especial. Una doble mirada al trabajo infantil en Colombia. https: / / www.icbf.gov.co/sites/default/ files/ publicacion-40.pdf

Instituto Colombiano de Bienestar Familiar (ICBF). (2018). Procesos Adminisrativos de Restablecimiento de Derechos - PARD. https: / / bit.ly /3vKwUc3 
Lina María Ortegón Suárez - Trata de personas en los niños, niñas y

Linares Cantillo, B. (2007). Código de la infancia y la adolescencia. Versión comentada. Canadian Internacional Development Agency. Unicef. https://uni. cf/30J021A

Ministerio del Interior y Oficina de Naciones Unidas contra la Droga y el Delito (UNODC). (2009). Estudio nacional exploratorio descriptivo sobre el fenómeno de trata de personas en Colombia. https: / / bit.ly/3rMAC2j

Ministerio del Interior. (2018). Pueblo Achagua. https: / bit.ly/30HmUlu

Moreno, A., Arribas, M. L. y Carrasco, L. (2019). Cultura grecolatina: Roma. Universidad Nacional de Educación a Distancia.

Oficina de Naciones Unidas contra la Droga y el Delito (UNODC). (2015). Estudio descriptivo del delito de trata de personas que victimiza a niñas y mujeres en Medellin. https: / / bit.ly/3eFlwYP

Oficina de Naciones Unidas contra la Droga y el Delito (UNODC). (2018). Global Report on Trafficking in Persons 2018. https: / / bit.ly/2Q23rKn

ONU. Asamblea General. (2000). Protocolo para prevenir, reprimir y sancionar la trata de personas, especialmente mujeres y niños, que complementa la Convención de las Naciones Unidas contra la Delincuencia Organizada Transnacional. https: / / www.refworld.org.es/ docid/50ab8f392.html

Organización Nacional Indígena de Colombia (ONIC). (2020). Achagua. https: / / bit. ly/3ca1a8F

Pabón Parra, P. A. (2018). Código de la infancia y la adolescencia: Esquemático. Ediciones Doctrina y Ley.

Pradilla-Rivera, S. J. (2011). Aplicación del principio del interés superior del niño(a) como mecanismo para proteger el derecho de los niños y las niñas a tener una familia y a no ser separados de ella. Estudios Socio-Jurídicos, 13(1), 329348. https: / / bit.ly/30DvB01

Reyes Jaimes, J., Vargas Parra, J. y Aceros, J. (2018). Análisis de las medidas de asistencia a víctimas de trata de personas en Colombia en perspectiva de derechos humanos. Opinión Jurídica, 17(33), 99-121. https:/ / doi. org/10.22395/ ojum.v17n33a4

Unicef. (2019). Día Mundial contra la Trata de Personas. https: / / uni.cf/2NeKWkK 